\title{
Fibromyalgia as a Heterogeneous Condition: Subgroups of Patients Based on Physical Symptoms and Cognitive-Affective Variables Related to Pain
}

\author{
M. Pilar Martínez (D), Ana I. Sánchez (D), Germán Prados (D), María J. Lami iD, Beatriz Villar and \\ Elena Miró (D) \\ Universidad de Granada (Spain)
}

\begin{abstract}
Fibromyalgia (FM) is a chronic syndrome characterized by heterogeneous clinical manifestations, and knowing this variability can help to develop tailored treatments. To understand better the heterogeneity of FM the present crosssectional study analyzed the role of several physical symptoms (pain, fatigue and poor sleep quality) and cognitive-affective variables related to pain (pain catastrophizing, pain vigilance, self-efficacy in pain management, and pain acceptance) in the configuration of clinical profiles. A sample of 161 women with FM fulfilled an interview and several self-report measures to explore physical symptoms, cognitive-affective variables, disability and psychopathology. To establish FM groups a hierarchical cluster analysis was performed. The findings revealed three clusters that differed in the grouping variables, Wilks' $\lambda=.17, F(14,304)=31.50, p<.001, \eta_{\mathrm{p}^{2}}=.59$. Group $1(n=72)$ was characterized by high physical and psychological affectation, Group $2(n=19)$ by low physical affectation and high pain self-efficacy, and Group $3(n=70)$ by moderate physical affectation and low pain catastrophizing. The external validation of the clusters was confirmed, Wilks' $\lambda=.72, F(4,314)=$ $14.09, p<.001, \eta_{\mathrm{p}^{2}}=.15$, showing Group 1 the highest levels of FM impact and psychopathological distress. Considering the distinctive clinical characteristics of each subgroup therapeutic strategies addressed to the specific needs of each group were suggested. Assessing FM profiles may be key for a better understanding and approach of this syndrome.
\end{abstract}

Received 26 November 2020; Revised 29 March 2021; Accepted 30 March 2021

Keywords: cluster analysis, cognitive-affective variables, fibromyalgia, physical symptoms, subgroups

Fibromyalgia (FM) is a complex and disturbing chronic pain syndrome. Lacking objective biomarkers, the diagnosis of this disease is based on clinical evaluation and patient report of widespread musculoskeletal pain and concomitant symptoms such as fatigue, insomnia, morning stiffness, emotional distress, and cognitive problems (Galvez-Sánchez \& Reyes del Paso, 2020). In Spain the prevalence of $\mathrm{FM}$ is $2.45 \%$, being more common in women than in men and concentrating almost half of the cases in the age group of 40-59 years (Font et al., 2020). This disease has an important impact on the person's life. FM patients often have difficulties with their partner, depend

Correspondence concerning this article should be addressed to M. Pilar Martínez. Departamento de Personalidad, Evaluación y Tratamiento Psicológico de la Universidad de Granada. Campus Universitario de Cartuja. 18071 Granada (Spain).

E-mail: mnarvaez@ugr.es

Conflicts of Interest: None.

Funding Statement: This work is part of a broader research project supported by the Spanish Ministry of Economy and Competitiveness (grant number PSI2014-58379-P) and Spanish State Research Agency (grant number PID2019-109612GB-I00/ AEI/ 10.13039/501100011033). on a family member for household chores, and lose their capacity to work (Collado et al., 2014).

From a biopsychosocial perspective, FM is considered as result of a multicausal process in which genetic factors, dysfunctions of the central and autonomic nervous systems, neuroendocrine and inmunological aspects, external stressors, and psychological characteristics, among others, may be involved (Bellato et al., 2012). Also, FM is a heterogeneous disorder as evidenced by the wide variety of physical symptoms, functioning limitations, cognitive-affective responses, and comorbidity manifested by patients (Auvinet \& Chaleil, 2012; Belenguer et al., 2009). Despite research in pharmacological and non-pharmacological treatments, no

How to cite this article:

Martínez, M. P., Sánchez, A. I., Prados, G., Lami, M. J., Villar, B., \& Miró, E. (2021). Fibromyalgia as a heterogeneous condition: Subgroups of patients based on physical symptoms and cognitive-affective variables related to pain. The Spanish Journal of Psychology, 24. e33. Doi:10.1017/SJP.2021.30 
single option has been identified as universally effective for all FM patients (Okifuji \& Hare, 2013). For this reason, in recent years the need to establish subgroups of FM patients to guide a more individualized management has been emphasized (Häuser et al., 2018). So, knowing the underlying variability of FM can help to better understand the etiopathogenic mechanisms involved in this syndrome and to design customized treatments that respond optimally to the specific needs of each patient.

Over the past 2 decades, a number of attempts have been made to identify subsets of FM patients who share common characteristics. While some classifications have been performed considering psychophysiological responses (Thieme \& Turk, 2006; Thieme et al., 2015) and history of childhood maltreatment and biomarkers (Loevinger et al., 2012), most of them have been established according to psychosocial features derived of self-reports measures. In this last set of studies it may be differentiated among approaches focused on symptomatology, focused on personality variables/processes, and mixed.

From an approach focused on symptomatology, and via the Multidimensional Pain Inventory (MPI) that allows to identify 3 subgroups (dysfunctional, interpersonally distressed, and adaptive coppers), in FM patients Turk et al. (1996) observed that dysfunctional and interpersonally distressed subgroups reported higher pain, disability, and depression, and interpersonally distressed subgroup also reported significantly lower marital satisfaction, and Thieme et al. (2004) found that dysfunctional subgroup mainly reported anxiety, interpersonally distressed subgroup mood disorders, and adaptive coppers subgroup reduced comorbidity with mental disorders. Considering the Fibromyalgia Impact Questionnaire (FIQ), De Souza et al. (2009) identified in FM patients two subgroups: Type I characterized by low levels of anxiety, depression and morning tiredness, and Type II characterized by high levels of pain, fatigue, morning tiredness, stiffness, anxiety and depression. Later studies have broadened the characteristics of this typology (Calandre et al., 2011; Salgueiro et al., 2012; Triñanes et al., 2014). For example, Calandre et al. (2011) found that Type II showed greater medical comorbidities and prescribed drugs, worse sleep quality, more physical ill and psychological distress. Applying the FIQ-revised it was identified three subgroups (Salaffi et al., 2016) and a four-cluster solution (reflecting different levels of FM severity) validated taking into account clinical measures, economic costs, inflammatory markers levels, and gray matter volumes (Pérez-Aranda et al., 2019).

From an approach focused on personality variables/ processes several categorizations of FM patients have been established. For example, Torres et al. (2013) via the NEO Five-Factor Inventory identified two clusters, one of them showed higher neuroticism and lower extraversion and worse pretreatment clinical state including more psychosocial problems, and the other presented better adaptation. Similarly, Gonzalez et al. (2020) using the Minnesota Multiphasic Personality Inventory-2 found two groups, one of them characterized by higher negative emotionality and introversion, presented a more disturbed profile in terms of general maladjustment, symptomatic behavior and clinical problem areas.

From a mixed approach, some studies have performed classifications of FM patients based on psychological features and other clinical aspects. Solutions between three and five clusters have been established considering musculoskeletal, non-musculoskeletal and cognitive/psychological domains (Wilson et al., 2009), descriptors of sensory abnormalities and comorbities (Rehm et al., 2010), personal/family history of medical/psychopathological comorbidities, disease evolution, clinical scales and somatic symptoms (Docampo et al., 2013), pain, fatigue, function, sleep disturbance, depression, anxiety, dyscognition and stiffness (Vincent et al., 2014), cognitive performance, physical performance, anxiety and depression (Follick et al., 2016), pain, functioning, anxiety, depression and social support (Yim et al., 2017), and pain intensity, pain unpleasantness, fatigue, anxiety and depression (Bartley et al., 2018). Possibly this mixed approach, compared to the previous ones, has the advantage of capturing the patterns of manifestations of FM in a more complete and varied way, showing greater ecological validity.

From this approach are of special interest the classifications of FM patients that have included cognitiveaffective variables related to pain. Note that according to the influential Fear-Avoidance Model of Musculoskeletal Pain (Leeuw et al., 2007) these variables (e.g., pain catastrophizing, fear of pain and pain vigilance) are involved in the exacerbation of pain experience and disability. Giesecke et al. (2003) considering mood, cognitive and pain sensitivity variables identified via a hierarchical cluster analysis (HCA) in 97 FM patients three subgroups: Subgroup 1 exhibited moderate anxiety, depression, pain catastrophizing and perceived control over pain, and low tenderness; Subgroup 2 exhibited high anxiety, depression and tenderness, the highest pain catastrophizing, and the lowest perceived control over pain; and Subgroup 3 exhibited normal anxiety and depression, very low pain catastrophizing, and the highest perceived control over pain and tenderness. However, the Giesecke et al.'s threecluster model was not replicated by Luciano et al. (2016) in $160 \mathrm{FM}$ patients. Applying a HCA a two-cluster solution (functional and hypersensitive groups) emerged, whereas using a latent profile analysis (LPA) a three-class model was identified: Functional profile 
defined by moderate tenderness, distress and pain catastrophizing, dysfunctional profile defined by high tenderness, distress and pain catastrophizing, and highly dysfunctional and distressed profile defined by high tenderness and extremely elevated distress and pain catastrophizing (Luciano et al., 2016). Plazier et al. (2015) based on physical symptoms, disability, health status, pain catastrophizing, pain vigilance, and emotional distress applying a HCA in 65 FM patients identified three subgroups: Subgroup 1 reflected high mood and catastrophizing-related symptoms and decreased mental health, Subgroup 2 reflected high fatigue and decreased physical health, and Subgroup 3 reflected a mixture of these two subgroups. Estévez-López et al. (2017) based on declarative memory, active lifestyle, physical fitness, fatigue, psychological distress, pain catastrophizing, and resilience applied a HCA in 486 FM patients and identified five subgroups: Adapted, fit, poor performed, positive and maladapted. Finally, Muller et al. (2020) considering self-efficacy, resilience, coping, social support, social stigma, perceived stress, anxiety, cognitive impairment, pain intensity, fatigue, and sleep problems, and via a HCA in 302 FM patients identified three subgroups reflecting moderate, least and many biopsychosocial problems, but in this study pain appraisal variables were not included.

Although previous research considered important psychological characteristics associated with FM to establish subgroups, only a few studies contemplated cognitive-affective variables related to pain and none of them included pain acceptance, an important protective factor from FM impact. In the last few years pain acceptance has been proposed as a crucial concept that extends the Fear-Avoidance Model of Musculoskeletal Pain (Crombez et al., 2012), and as one of the interrelated processes (along with cognitive defusion, flexible present-focused attention, self-as-observer, values, and committed action) included in the Psychological Flexibility Model (McCracken \& Morley, 2014) for the management of chronic pain. Pain acceptance is defined as the willingness to live with pain with no need to try to change it (Thompson \& McCracken, 2011) and evidence suggests that contributes in a powerful way to developing a more constructive pain experience. In FM patients several studies found that pain acceptance was associated with lower emotional distress and disability (Lami et al., 2018), and better functional level and less symptoms (Tangen et al., 2020), and that pain-related psychological flexibility and general psychological acceptance were related to functional status (Trainor et al., 2019). Surprisingly, despite this evidence, no study has considered pain acceptance as a variable of interest in the configuration of FM subgroups.

To understand better the heterogeneity of FM the present cross-sectional study analyze the role of pain acceptance along with other cognitive-affective and physical variables in the configuration of differentiated subsets of patients. The selection of grouping variables was in line with previous research (mixed approach) and additionally incorporated pain acceptance as a key feature that had not been considered so far in this type of study. Knowing how these variables and their combinations reflect specific clinical clusters that entail certain needs and require personalized therapeutics can be of great practical interest. Further, it is well known that FM is frequently linked to high functional impairment and psychological distress, so in order to evaluate how well the clustering findings match to this prior knowledge disability and psychopathology were taken as criteria for external validation. Thus, the objectives of this study were: i) to identify subgroups of FM patients characterized by a specific constellation of physical manifestations (pain, fatigue and poor sleep quality) and cognitive-affective responses to pain (pain catastrophizing, pain vigilance, self-efficacy in pain management, and pain acceptance). ii) to analyze whether the FM subgroups identified differ in disability and psychopathology. We hypothesized that FM patients with more favorable cognitive-affective responses will show better adaptation to the disease (expressed as less disability and psychopathology).

\section{Method}

\section{Patients}

Considering that female sex is the variable most associated with FM in prevalence reports in Spain (e.g., Font et al., 2020) in the present study only women were included. Participants were recruited from the Virgen de las Nieves University Hospital (Rheumatology Service) and several FM associations. The inclusion criteria to participate in this study were the following: (a) Be a woman between 18 and 67 years old; (b) have adequate reading comprehension; and (c) have a diagnosis of FM according to the criteria of the American College of Rheumatology (Wolfe et al., 1990, 2010). The presence of other rheumatic/pain problems, relevant medical diseases or pregnancy, psychological disorder with severe symptoms, and history of alcoholism/substance addiction were exclusion criteria. Applying a consecutive sampling and the eligibility criteria, the final sample included 163 women with FM (see Appendix).

\section{Measures}

Measures for Cluster Derivation: Physical Symptoms and Cognitive-Affective Variables related to Pain

McGill Pain Questionnaire-Short Form (MPQ-SF; Melzack, 1987). The MPQ-SF evaluates pain experience 
with 15 sensory/affective descriptors, pain intensity during the previous week with a visual analogue scale (VAS) from no pain (1) to extreme pain (10), and pain intensity at the time of the test. In this study the VAS was selected considering that offers a more stable measure of pain and that it is in line with the time range of evaluation of the remaining measures used. The VAS has good sensitivity and specificity, and these values are considerably similar to those of dolorimetry (Marques et al., 2008).

Multidimensional Fatigue Inventory (MFI; Smets et al., 1995; adaptation by Fillion et al., 2003). The MFI comprises 20 items that evaluate general fatigue, physical fatigue, mental fatigue, reduced motivation, and reduced activity. Items are assessed on a scale ranging from not agree (1) to completely agree (5). The Spanish version of the MFI showed good reliability, and construct validity in FM patients (Munguía-Izquierdo et al., 2012). In this study the general fatigue subscale was used (scores can vary from 1 to 5 , high scores indicating greater fatigue). This domain was selected because includes general statements concerning to person functioning and it is the scale that shows better test-retest reliability and the highest associations to the VAS for global fatigue (Munguía-Izquierdo et al., 2012).

Pittsburgh Sleep Quality Index (PSQI; Buysse et al., 1989). The PSQI includes 19 items that explore subjective sleep quality, sleep latency, sleep duration, habitual sleep efficiency, sleep disturbances, use of sleeping medication, and daytime dysfunction. The total-scale score ranges from 0 to 21 (high scores indicating greater disturbance). The Spanish version of the PSQI showed adequate internal consistency, test-retest reliability, and convergent validity in FM patients (Hita-Contreras et al., 2014).

Pain Catastrophizing Scale (PCS; Sullivan et al., 1995). The PCS consists of 13 items that evaluate magnification, rumination, and helplessness. Items are assessed on a scale from not at all (0) to all the time (4), and the totalscale score ranges from 0 to 52 (high scores indicating greater pain catastrophizing). The Spanish version of the PCS showed good internal consistency, test-retest reliability and sensitivity to change in FM patients (García-Campayo et al., 2008).

Pain Vigilance and Awareness Questionnaire (PVAQ; McCracken, 1997). The PVAQ includes 16 items that assess awareness, consciousness, vigilance and observation of pain. Items are measured on a scale from never (0) to always (5), and the total-scale score ranges from 0 to 80 (high scores indicating greater pain vigilance). The Spanish version of the PVAQ showed good internal consistency, convergent validity, and divergent validity in FM patients (Martínez, Miró, Sánchez, Lami, et al., 2014).

Chronic Pain Self-efficacy Scale (CPSS; Anderson et al., 1995). The CPSS comprises 19 items that explore self-efficacy expectations regarding pain management, coping with symptoms, and physical function. Items are measured on a scale from totally incapable (0) to totally capable (10), and the total-scale score ranges from 0 to 190 (high scores indicating greater self-efficacy). The Spanish version of the CPSS showed good construct validity and internal consistency (Martín-Aragón et al., 1999).

Chronic Pain Acceptance Questionnaire (CPAQ; McCracken et al., 2004). The CPAQ includes 20 items that assess activity engagement and pain willingness. Items are measured on a scale from never true (0) to always true (6), and the total-scale ranges from 0 to 120 (high scores indicating greater pain acceptance). The Spanish version of the CPAQ showed adequate test-retest reliability, internal consistency, and construct validity in FM patients (Rodero et al., 2010).

\section{Measures for External Validation: Disability and Psychopathology}

Fibromyalgia Impact Questionnaire (FIQ; Burckhardt et al., 1991). The FIQ consists of 10 items that explore the current health status of FM patients. Item 1 assesses functional capacity for daily living ranged from always (0) to never (3). Items 2 and 3 ask the patient to mark the number of days in last week he/she felt well/unable to work (ranged from 0 to 7 days). Items 4 through 10 are scales marked in 10 levels which evaluate work difficulty, pain, fatigue, morning tiredness, stiffness, anxiety, and depression. The total-scale score ranges from 0 to 100 (high scores indicating greater impact). The Spanish version of the FIQ showed good test-retest reliability, internal consistency, validity, and sensitivity to change (Rivera \& González, 2004).

Symptom Checklist-90-Revised (SCL-90-R; Derogatis, 1994). The SCL-90-R evaluates psychopathological symptoms through 90 items estimated on a scale from not at all (0) to very much or extremely (4). It includes 9 primary dimensions (somatization, obsessivecompulsive, interpersonal sensitivity, depression, anxiety, hostility, phobic anxiety, paranoid ideation and psychoticism) and 3 global indices (global severity index, positive symptom total, and positive symptom distress index, PSDI). In this study the PSDI was used (the score ranges from 0 to 4 , high scores indicating greater distress). The PSDI measures the intensity of the symptoms perceived and reflects the person's characteristic style of expression psychic distress. The Spanish version of the SCL-90-R showed adequate reliability and validity (González de Rivera et al., 2002).

\section{Procedure}

Participants were administered an interview to gather information on demographic and clinical data. After the 
interview a booklet of self-report measures about physical symptoms, cognitive-affective variables, disability and psychopathology was delivered that the person had to complete at home, setting a new appointment for delivery within a maximum of one week (or facilitating any other way of delivery). The study was approval by the Ethics Committee of the Universidad de Granada, and all patients signed an informed consent document to collaborate in the study.

\section{Data Analysis}

Since it is necessary to have a sample size of at least $2^{m}$ participants (where $m=$ number of clustering variables) for a cluster analysis (Formann, 1984), in the present study, $m=7$ and a minimum of 128 subjects was required. Therefore, the sample recruited $(n=$ 163 women with FM) was adequate.

All analyses were performed using the SPSS 20.0 software. For statistical significance a level of $p<.05$ was considered. As a preliminary step missing values of data were imputed with fully conditional specification method (MCMC), and outliers were identified using Mahalanobis distance and excluded of the sample. Pearson correlation coefficient between the measures for cluster derivation was computed to confirm that data were suitable to perform the cluster analysis. In order to establish FM groups a HCA (agglomerative method) was performed. Squared Euclidean distance was considered in the proximities matrix. To form clusters at each stage Ward's method was applied. Standardized data ( $z-$ scores) were used to minimize the bias associated to different metric of variables. The optimal number of clusters was determined observing the percentage change in agglomeration coefficient between successive cluster solutions, and considering the clinical interpretability and parsimony of data (minimal number of groups). To explore the differences between FM groups in the variables for cluster derivation and in the variables for external validation, multivariate analyses of variance (MANOVAs) were computed. The differences between FM groups in each variable were examined via one-way ANOVAs (with Scheffé test for post-hoc contrasts). Finally, a discriminant function analysis was conducted to examine the relative weight of each clustering variable in discriminating between the FM groups.

\section{Results}

\section{Description of the Sample}

The characteristics of the sample $(n=163)$ are presented in Table 1 . The patients were women with an average age of 50.98 years. The majority was married $(82.2 \%)$, and had primary/secondary education $(61.1 \%)$, with $34.2 \%$ in active work status and $23.6 \%$ in sick leave due to
Table 1. Demographic and Clinical Characteristics of FM Patients $(n=163)$

\begin{tabular}{|c|c|c|c|}
\hline Variables & $\%$ & $M$ & $S D$ \\
\hline Age (years) & & 50.98 & 8.11 \\
\hline \multicolumn{4}{|l|}{ Education } \\
\hline Basic education & 29.6 & & \\
\hline High school & 31.5 & & \\
\hline Professional instruction & 16.7 & & \\
\hline University studies & 22.2 & & \\
\hline \multicolumn{4}{|l|}{ Marital status } \\
\hline Married & 82.2 & & \\
\hline Single & 6.7 & & \\
\hline Divorced & 7.4 & & \\
\hline Widowed & 3.7 & & \\
\hline \multicolumn{4}{|l|}{ Work status } \\
\hline Currently employed & 34.2 & & \\
\hline Retired & 13.7 & & \\
\hline Unemployed & 28.5 & & \\
\hline Disabled & 23.6 & & \\
\hline Duration of FM diagnosis (years) & & 7.31 & 6.12 \\
\hline \multicolumn{4}{|l|}{ Drug intake } \\
\hline Antidepressants & 64.9 & & \\
\hline Anxiolytics & 57.7 & & \\
\hline Anti-inflammatory drugs & 24.3 & & \\
\hline Analgesics & 46.8 & & \\
\hline Pain intensity (MPQ-SF) & & 7.53 & 1.42 \\
\hline General fatigue (MFI) & & 4.31 & 0.79 \\
\hline Poor sleep quality (PSQI) & & 13.88 & 4.34 \\
\hline Pain catastrophizing (PCS) & & 25.64 & 11.90 \\
\hline Pain vigilance (PVAQ) & & 45.67 & 12.20 \\
\hline Pain self-efficacy (CPSS) & & 74.52 & 32.11 \\
\hline Pain acceptance (CPAQ) & & 52.30 & 18.10 \\
\hline Disability (FIQ) & & 61.00 & 15.27 \\
\hline Psychopathology (SCL-90-R) & & 2.40 & 0.54 \\
\hline
\end{tabular}

Note. MPQ-SF = McGill Pain Questionnaire-Short Form; MFI = Multidimensional Fatigue Inventory; PSQI = Pittsburgh Sleep Quality Index; PCS = Pain Catastrophizing Scale; PVAQ = Pain Vigilance and Awareness Questionnaire; CPSS = Chronic Pain Self-efficacy Scale; CPAQ = Chronic Pain Acceptance Questionnaire; FIQ = Fibromyalgia Impact Questionnaire; SCL-90-R = Symptom Checklist-90-Revised.

disability. The patients had high/moderated scores in pain intensity and general fatigue, and poor sleep quality (cut-off point in PSQI > 5; Buysse et al., 1989). The levels of pain catastrophizing and pain vigilance were moderated and similar to those presented by FM patients from the study by Crombez et al. (2004). The levels of pain selfefficacy and pain acceptance were moderated and higher than those reported by FM patients in other studies (Lledó-Boyer et al., 2010; Rodero et al., 2010). The FM impact was severe (cut-off point in FIQ $\geq 59$; Bennett et al., 2009), and the level of psychopathology corresponded to 85th percentile of the group of healthy women (González de Rivera et al., 2002). 
Table 2. Comparison between FM Groups in Measures for Cluster Derivation

\begin{tabular}{|c|c|c|c|c|c|c|c|c|c|}
\hline & \multicolumn{2}{|c|}{$\begin{array}{c}\text { Cluster } 1 \\
(n=72)\end{array}$} & \multicolumn{2}{|c|}{$\begin{array}{c}\text { Cluster } 2 \\
(n=19)\end{array}$} & \multicolumn{2}{|c|}{$\begin{array}{l}\text { Cluster } 3 \\
(n=70)\end{array}$} & \multirow[b]{2}{*}{$F(2,158)$} & \multirow[b]{2}{*}{$\eta^{2}$} & \multirow[b]{2}{*}{ Pairwise } \\
\hline & $M$ & $S D$ & $M$ & $S D$ & $M$ & $S D$ & & & \\
\hline Pain intensity (MPQ-SF) & 8.12 & 1.34 & 7.21 & 1.23 & 7.08 & 1.38 & $11.19^{* *}$ & .12 & $a, b$ \\
\hline General fatigue (MFI) & 4.65 & 0.56 & 2.80 & 0.59 & 4.33 & 0.61 & $76.75^{* *}$ & .50 & $a, b, c$ \\
\hline Poor sleep quality (PSQI) & 16.32 & 2.96 & 8.26 & 4.21 & 12.82 & 3.76 & $45.61^{* *}$ & .37 & $a, b, c$ \\
\hline Pain catastrophizing (PCS) & 35.22 & 7.38 & 22.63 & 11.26 & 16.60 & 7.85 & $94.93^{* *}$ & .55 & $a, b, c$ \\
\hline Pain vigilance (PVAQ) & 51.93 & 9.15 & 42.42 & 11.77 & 39.90 & 12.07 & $22.88^{* *}$ & .23 & $a, b$ \\
\hline Pain self-efficacy (CPSS) & 54.44 & 25.33 & 105.32 & 28.17 & 87.57 & 26.51 & $42.98^{* *}$ & .35 & $a, b, c$ \\
\hline Pain acceptance (CPAQ) & 40.13 & 13.16 & 60.27 & 19.43 & 62.56 & 14.46 & $45.32^{* *}$ & .37 & $a, b$ \\
\hline
\end{tabular}

Note. MPQ-SF = McGill Pain Questionnaire-Short Form; MFI = Multidimensional Fatigue Inventory; PSQI = Pittsburgh Sleep Quality Index; PCS = Pain Catastrophizing Scale; PVAQ = Pain Vigilance and Awareness Questionnaire; CPSS = Chronic Pain Selfefficacy Scale; $\mathrm{CPAQ}=$ Chronic Pain Acceptance Questionnaire. Significant post-hoc contrasts (Scheffé test, $p<.05)$ : (a) Cluster 1 vs. Cluster 2; (b) Cluster 1 vs. Cluster 3; (c) Cluster 2 vs. Cluster 3. The observed power in all analyses was $>.95$, calculated with $p=.05$. $* * p<.001$.

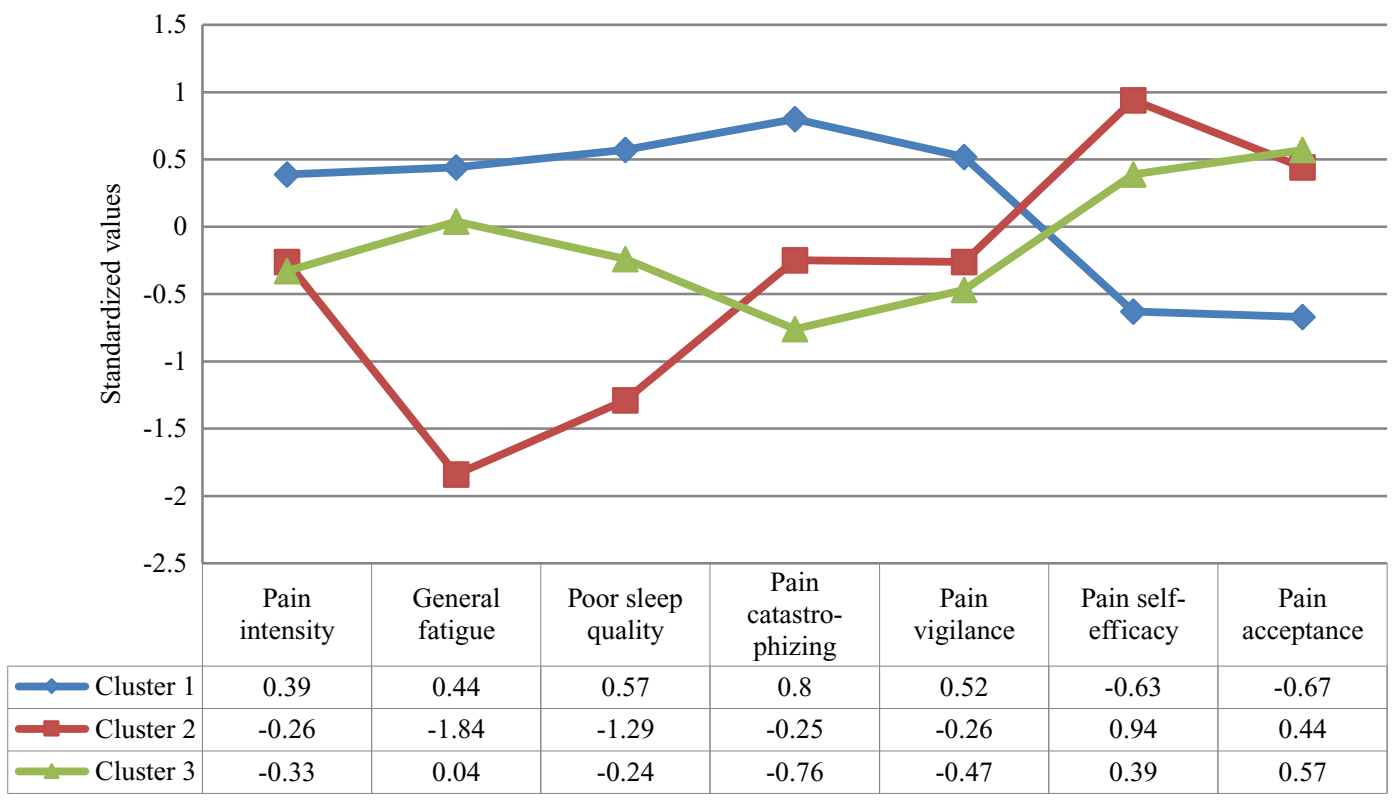

Figure 1. Profile of the Clusters in the Clinical Grouping Variables

\section{Clustering}

In the sample, $2.7 \%$ of lost values were identified and imputed. Two participants were excluded because they presented atypical values, leaving the sample consisting of 161 patients, an appropriate size to proceed with the cluster analysis. Correlational analysis revealed significant correlations between all variables, ranging from $r=$ $-.56(p<.01)$ to $r=.57(p<.01)$, except between pain intensity and general fatigue $(r=.08, p=.309)$ and between sleep quality and pain vigilance $(r=.10, p=.193)$.

Considering the agglomeration coefficients the first marked percentage change occurred from Stage 2 (coefficient $=0.000)$ to Stage 3 (coefficient $=0.119)$, so the solution of 3-cluster solution was identified as the most appropriated. Group 1 was integrated by 72 participants, Group 2 by 19, and Group 3 by 70 .

The MANOVA confirmed that the set of variables for the clusters derivation differentiated the groups, Wilks' $\lambda=.17, F(14,304)=31.50, p<.001, \eta_{\mathrm{p}^{2}}=.59$. Specifically, the one-way ANOVAs showed significant differences between the groups in each variable, between $F(2,158)=$ $11.19, p<.01$ and $F(2,158)=94.93, p<.01$ (see Table 2 and Figure 1). Considering the post-hoc contrasts, Group 1 differed significantly from the other groups in all aspects considered. Group 1 showed greater pain intensity and general fatigue, worse quality of sleep, greater 
Table 3. Coefficients of the Discriminant Functions of each Cluster

\begin{tabular}{|c|c|c|c|}
\hline Variable & $\begin{array}{c}\text { Cluster } \\
1\end{array}$ & $\begin{array}{c}\text { Cluster } \\
2\end{array}$ & $\begin{array}{c}\text { Cluster } \\
3\end{array}$ \\
\hline Constant & -2.45 & -6.46 & -1.86 \\
\hline Pain intensity (MPQ-SF) & 0.20 & -0.37 & -0.11 \\
\hline General fatigue (MFI) & 1.00 & -3.79 & -0.00 \\
\hline Poor sleep quality (PSQI) & 0.81 & -2.02 & -0.29 \\
\hline $\begin{array}{l}\text { Pain catastrophizing } \\
\text { (PCS) }\end{array}$ & 1.34 & 0.01 & -1.38 \\
\hline Pain vigilance (PVAQ) & 0.10 & 0.04 & -0.11 \\
\hline Pain self-efficacy (CPSS) & -0.25 & 0.91 & 0.01 \\
\hline Pain acceptance (CPAQ) & -0.66 & 0.48 & 0.55 \\
\hline
\end{tabular}

Note. MPQ-SF = McGill Pain Questionnaire-Short Form; MFI = Multidimensional Fatigue Inventory; PSQI = Pittsburgh Sleep Quality Index; PCS = Pain Catastrophizing Scale; PVAQ = Pain Vigilance and Awareness Questionnaire; $\mathrm{CPSS}=$ Chronic Pain Self-efficacy Scale; CPAQ = Chronic Pain Acceptance Questionnaire. The values of the variables with the highest coefficients are shown in bold.

pain catastrophizing and pain vigilance, and lower pain self-efficacy and pain acceptance than Groups 2 and 3 . Group 1 can be defined by high physical and psychological affectation. Taking into account the post-hoc contrasts, Group 2 differed significantly from Group 3 in several aspects. Group 2 showed less general fatigue, better quality of sleep, and greater pain self-efficacy than Group 3; while Group 3 presented less pain catastrophizing than Group 2. So, Group 2 can be defined by low physical affectation and high pain self-efficacy, and Group 3 by moderate physical affectation and low pain catastrophizing.

To identify the differentiating capacity of the variables, a discriminant analysis was carried out (see Table 3). Considering the greater load of each variable throughout the clusters, the findings revealed that: In Group 1 the most relevant variable was pain acceptance $(-0.66)$; in Group 2 were pain intensity, general fatigue, poor quality of sleep $(-0.37,-3.79$ and -2.02 , respectively) and pain self-efficacy (0.91); and in Group 3 were pain catastrophizing and pain vigilance $(-1.38$ and -0.11 , respectively).

\section{External Validation of Clusters}

The MANOVA indicated that the external validation variables differentiated between the clusters, Wilks' $\lambda=$ $.72, F(4,314)=14.09, p<.001, \eta_{\mathrm{p}^{2}}=.15$. The one-way ANOVAs showed significant differences between the groups in disability $F(2,158)=14.46, p<.01$, and psychopathology $F(2,158)=22.88, p<.01$ (see Table 4 ). The post-hoc contrasts showed that Group 1 had greater disability and psychopathology than Groups 2 and 3.

\section{Differences in Demographic Variables between Clusters}

The groups did not differ significantly in age $F(2,160)=$ 1.44, $p=.241$, education $\chi^{2}(10)=12.26, p=.268$, nor marital status $\chi^{2}(8)=8.25, p=.409$, however they differed in work status $\chi^{2}(10)=18.97, p=.041$, with the highest percentage of disabled in Group 1.

\section{Discussion}

This is the first study that examines the profiles of FM patients taking into account the role of pain acceptance, together with another key psychological variables (pain catastrophizing and pain vigilance) contemplated in the fear-avoidance model of musculoskeletal pain (Leeuw et al., 2007).

Cluster analysis in the FM sample revealed three conglomerates based on the severity of physical symptoms and cognitive-affective variables related to pain. Group 1 was characterized by highest levels of pain intensity, general fatigue, poor sleep quality, pain catastrophizing, and pain vigilance, and lowest levels of pain self-efficacy and pain acceptance. Group 2 showed the lowest level of general fatigue, moderated levels of pain intensity, pain catastrophizing, pain vigilance and pain acceptance, and the highest levels of sleep quality and pain self-efficacy. Group 3 displayed by the lowest level of pain intensity, pain catastrophizing and pain vigilance, moderated levels of general fatigue, sleep quality, and pain self-efficacy, and the highest level of pain acceptance. Significant differences were observed in all variables between Group 1 and Groups 2 and 3, with Group 1 showing the most dysfunctional profile. Likewise, significant differences were observed between Group 2 and Group 3, with Group 2 exhibiting less general fatigue, better sleep quality, and greater pain self-efficacy than Group 3, and Group 3 showing less pain catastrophizing than Group 2. The variables with greater discriminative power were general fatigue, sleep quality and pain catastrophizing. Regarding the external validity of the identified conglomerates, only significant differences were found between Group 1 and Groups 2 and 3, with Group 1 showing the highest levels of FM impact and psychopathological distress. Probably the greater self-efficacy and less catastrophizing could account for the better clinical status of patients in Groups 2 and 3, confirming the hypothesis raised.

Taking into account the most dysfunctional profile represented by Group 1, the low pain acceptance seems to be a relevant variable linked to severity of FM, which is in line with previous research (e.g., Lami et al., 2018; Tangen et al., 2020; Trainor et al., 2019). However, beyond the low pain acceptance, other processes of psychological inflexibility may be involved in FM experience. For example, there is evidence that cognitive fusion is associated with poorer functioning indirectly 
Table 4. Comparison between FM Groups in Measures for External Validation

\begin{tabular}{|c|c|c|c|c|c|c|c|c|c|c|c|c|}
\hline & \multicolumn{2}{|c|}{$\begin{array}{c}\text { Cluster } 1 \\
(n=72)\end{array}$} & \multicolumn{2}{|c|}{$\begin{array}{c}\text { Cluster } 2 \\
(n=19)\end{array}$} & \multicolumn{2}{|c|}{$\begin{array}{c}\text { Cluster } 3 \\
(n=70)\end{array}$} & \multirow[b]{2}{*}{$F(2,158)$} & \multirow[b]{2}{*}{$\eta^{2}$} & \multirow[b]{2}{*}{$M D$} & \multirow[b]{2}{*}{$S E$} & \multicolumn{2}{|c|}{$95 \% \mathrm{CI}$} \\
\hline & $M$ & $S D$ & $M$ & $S D$ & $M$ & $S D$ & & & & & LL & UL \\
\hline Disability (FIQ) & 67.92 & 13.85 & 54.52 & 16.23 & 56.12 & 14.21 & $14.46^{* *}$ & .16 & & & & \\
\hline Pairwise a & & & & & & & & & $13.40^{*}$ & 3.69 & 4.29 & 22.51 \\
\hline Pairwise b & & & & & & & & & $11.80^{*}$ & 2.40 & 5.87 & 17.73 \\
\hline Pairwise c & & & & & & & & & -1.60 & 3.70 & -10.73 & 7.54 \\
\hline $\begin{array}{l}\text { Psychopathology } \\
\text { (SCL-90-R) }\end{array}$ & 2.69 & 0.46 & 2.11 & 0.57 & 2.19 & 0.47 & $22.88^{* *}$ & .23 & & & & \\
\hline Pairwise a & & & & & & & & & $0.57^{*}$ & 0.12 & 0.27 & 0.88 \\
\hline Pairwise b & & & & & & & & & $0.49^{*}$ & 0.08 & 0.30 & 0.69 \\
\hline Pairwise c & & & & & & & & & -0.08 & 0.12 & -0.38 & 0.22 \\
\hline
\end{tabular}

Note. FIQ = Fibromyalgia Impact Questionnaire; MD = Mean Difference; SCL-90-R = Symptom Checklist-90-Revised. Significant post-hoc contrasts (Scheffé test, $p<.05$ ): (a) Cluster 1 vs. Cluster 2; (b) Cluster 1 vs. Cluster 3; (c) Cluster 2 vs. Cluster 3 . The observed power in all analyses was $>.95$, calculated with $p=.05$.

${ }^{*} p<.05$;

$* * p<.001$.

through FM symptoms (Écija et al., 2020). The contribution of other facets of psychological inflexibility is a relevant issue that needs further research.

Greater attention requires the distinction between Groups 2 and 3 that reflect more adaptive profiles. In fact, the differences between both clusters correspond to pain self-efficacy and the most discriminating variables (general fatigue, poor sleep quality and pain catastrophizing), which is in line with the classifying role of these features showed in previous studies (e. g., Estévez-López et al., 2017; Giesecke et al., 2003; Luciano et al., 2016; Muller et al., 2020; Plazier et al., 2015). It is possible that the peculiarities of Groups 2 and 3 are due to the fact that pain self-efficacy and pain catastrophizing and its complex interaction play a different role in fatigue, sleep quality and pain, determining differentiated profiles. In this sense, it was observed in patients with chronic pain that pain self-efficacy attenuated pain intensity's direct effect on depressive symptoms and its indirect effect on depressive symptoms via pain catastrophizing and both effects were reduced in a dosedependent manner (Cheng et al., 2018). Investigating the pathways of reciprocal influence between physical factors and protective and exacerbating cognitiveaffective factors using structural equations models can shed light on this question in FM.

In general, the findings of the present study show that pain acceptance is not an especially critical variable in the establishment of clinical profiles in FM patients. Rather, it seems that its potential contribution is partially overshadowed by the more powerful action of other pain-related cognitive-affective variables such as catastrophizing and self-efficacy. This trend was also observed in previous studies that showed the relevant contribution of self-efficacy on pain intensity and functional/psychological adjustment to FM and the less salient role of pain acceptance (Sahar et al., 2016), and that pain catastrophizing mediated the relationship between pain and depression/anxiety but pain acceptance no played a mediating role in these relationships (Lami et al., 2018). Acceptance may have a greater favourable influence when combined with other psychological features of resilience, although this is something that research needs to examine.

The present study replicated the findings of Giesecke et al. (2003), Plazier et al. (2015), and Luciano et al. (2016) regarding the number of groups identified and the relevance of pain catastrophizing in the profiling of the conglomerates. However, it was not possible a detailed comparison between the present study and previous studies given the different variables considered and instruments used to evaluate the same variable, which may mean that the same construct is not being captured in all the studies.

Identification of profiles of FM patients based on clinically important features have practical value in terms of patient-orientated therapeutic approaches. Some studies have observed differential response to interdisciplinary treatment among FM patients classified according to the MPI. Turk et al. (1998) reported that the dysfunctional subgroup exhibited significant reductions in pain, psychological distress, and disability, the interpersonally distressed subgroup showed no changes in these parameters, and the adaptive copper 
subgroup only reported significant improvements in pain. Verra et al. (2009) reported that the greatest improvements in pain severity, pain interference and physical functioning were showed by the dysfunctional group.

Other studies have recommended specific therapeutic strategies based on the FM profiles. Giesecke et al. (2003) suggested that patients with moderate distress might not need cognitive-behavioral therapy (CBT), patients with high distress might benefit from CBT and antidepressant and other psychotropic drugs, whereas patients with normal distress but highest hyperalgesia could better respond to antidepressant drugs with analgesic properties. Thieme et al. (2004) proposed that dysfunctional patients might benefit from a therapy focused on modification of solicitous responses by significant others and the management of anxiety disorders associated; interpersonally distressed patients might benefit from a therapy focused on interpersonal problem-solving and communication skills and the management of comorbid depression; and adaptive coppers patients might benefit from an approach focused on exercise and support without additional psychological therapy. Luciano et al. (2016) suggested that education, aerobic exercise and some medications would be sufficient for the functional group, and CBT or acceptance and commitment therapy could be additional beneficial components for dysfunctional and highly dysfunctional and distressed groups, in low-intensity and high-intensity, respectively. Yim et al. (2017) recommended for highly dysfunctional patients intensive pharmacological therapy, for lower dysfunctional patients non-pharmacological therapy (CBT, exercise and self-management strategies) and for the middle dysfunctional patients pharmacological and/or non-pharmacological interventions based on the dominant symptoms.

The FM profiles identified in the present study seem to show a continuum of severity and a remarkable concordance between the levels of physical symptoms and the levels of cognitive-affective variables related to pain. So, matching clinical needs of FM patients with the psychological strategies can lead to better care of the patients. Group 1 that presents the greatest physical and psychological affectation, and is the conglomerate in which the low pain acceptance becomes more relevant, could benefit from CBT for insomnia (Martínez, Miró, Sánchez, Díaz-Piedra, et al., 2014) or CBT for pain and insomnia (Prados et al., 2020) (education, sleep hygiene, bed time restriction, stimulus control, physiological deactivation techniques, activity-rest adjustment, communication and problem solving training, and cognitive restructuring to change dysfunctional thoughts related to pain and sleep) combined with elements of acceptance/mindfulness-based interventions (Veehof et al., 2016) (training in psychological flexibility via acceptance of experience, cognitive defusion, present moment awareness, sense of self as-context, valued life directions and committed actions, and training in intentional and non-judgmental awareness via meditation). Groups 2 and 3 that have a more functional profile than Group 1, would require a less intensive and prolonged therapeutic approach in which the components of CBT would be differentially emphasized depending on the preponderance of the symptoms. For Group 2, characterized by low physical affectation and moderate pain catastrophizing, cognitive restructuring focused on replacing dysfunctional thoughts about pain for more adaptive ones would be the best option. For Group 3 , characterized by a moderate physical affectation and a low psychological affectation, strategies aimed at improving sleep (sleep hygiene, bed time restriction, stimulus control, and physiological deactivation techniques), and an adequate regulation of levels of activity and rest to alleviate fatigue would be recommended. Consider that Group 2 is probably an "atypical" group due to its better level of adaptation, since the usual is that FM notably affects the physical and emotional functioning of the person. In fact, most of the FM patients perceive themselves with moderate to severe disability (Horta-Baas \& Romero-Figueroa, 2019), and show more difficulty adjusting to the disease and generally use poorer strategies to cope with pain than patients with other rheumatic diseases (Bucourt et al., 2019).

In the last years the CBT has acquired an increasingly prominent role in the integral approach to FM and can be an excellent treatment option for many patients with this pain condition. In this sense, several evidence-based clinical guidelines assign the highest level of recommendation to aerobic exercise, CBT, amitriptyline, and multicomponent treatment in the management of FM (Thieme et al., 2017). Also, several studies show the efficacy and tolerability of CBT and acceptance-based therapies in reducing key clinical manifestations of FM compared to control interventions (see review by Bernardy et al., 2018), and there is evidence to reveals that acceptance and commitment therapy (ACT) is beneficial in improving physical and emotional functioning in FM patients (see review by Hegarty et al., 2020). However, and although the differential efficacy between CBT and mindfulness-based therapies in chronic pain has been examined, no support of clear differences between both approaches has been found (see review by Pardos-Gascón et al., 2021). Thus, it is necessary to acquire more knowledge about "what works for whom" and the delimitation of clinical profiles in FM patients can be key to making decisions about the care of these patients.

This study presents several limitations. All measures were based on self-reports, and other objective 
measures to evaluate physical symptoms (e.g., tenderness via algometer or sleep quality via polysomnography) and the impact of FM (e.g., frequency of medical visits, medications consumption, days off work) would have provided relevant complementary information. Also, biomarkers were not available in this study. The sample consisted of middle-aged adult women with FM, so the findings could not be transferred to patients with other demographic characteristics. Finally, FM patients were not suffered associated diseases, so it is possible that FM patients with important comorbidity (physical and/or mental) could show different profiles to those identified in the present study.

With a view to future research, it would be necessary to examine the consistency of the clusters identified in other samples of FM patients, the confirmation of the optimal number of clusters via complementary statistical methods (e.g., latent profile analysis), the replicability of findings using revised versions of the self-reports (e.g., FIQ-revised), as well as the stability along the time of the clusters. Likewise, and given the key role of fatigue in FM patients (Velasco-Furlong et al., 2020), it would be of great interest to examine whether the dimensionality of fatigue is also reflected in the establishment of clusters. It would also be of remarkable clinical utility to establish the predictive value of the classification generated by analyzing the differential response of each subgroup to CBT. In addition, it would be convenient to include other variables such as resilience (Alonso-Tapia et al., 2018) and stress biomarkers (Arco García et al., 2020) for the establishment of subgroups.

In conclusion, there were at least three subgroups of FM patients based on the pattern of physical and cognitive-affective characteristics with important implications for individuals and health care system. The assessment of psychological aspects is crucial to delineate the optimal management of patients according to their clinical needs. Future research faces the challenge of identifying and validating which psychological therapies can be most beneficial in each profile.

\section{References}

Alonso-Tapia, J., Garrido-Hernansaiz, H., Rodríguez-Rey, R., Ruiz Díaz, M., \& Nieto, C. (2018). Evaluating resilience: Development and validation of the situated subjective resilience questionnaire for adults (SSRQA). The Spanish Journal of Psychology, 21, Article E39. https://doi.org/ 10.1017 /sjp.2018.44.

Anderson, K. O., Dowds, B. N., Pelletz, R. E., Edwards, W. T., \& Peeters-Asdourian, C. (1995). Development and initial validation of a scale to measure self-efficacy beliefs in patients with chronic pain. Pain, 63(1), 77-83. https:/ / doi.org/10.1016/0304-3959(95)00021-J.

Arco García, L., González Pérez, R., Henares Extremera, A., García León, M. A., \& Peralta-Ramírez, M. I. (2020).
Psychological and sociodemographic variables related to cortisol in hair in Spanish healthy population. The Spanish Journal of Psychology, 23, Article E14. https: / / doi.org/ 10.1017/SJP.2020.16.

Auvinet, B., \& Chaleil, D. (2012). Identification of subgroups among fibromyalgia patients. Reumatismo, 64(4), 250-260. https://doi.org/10.4081/reumatismo.2012.250.

Bartley, E. J., Robinson, M. E., \& Staud, R. (2018). Pain and fatigue variability patterns distinguish subgroups of fibromyalgia patients. The Journal of Pain, 19(4), 372-381. https:/ / doi.org/10.1016/j.jpain.2017.11.014.

Belenguer, R., Ramos-Casals, M., Siso, A., \& Rivera, J. (2009). Clasificación de la fibromialgia: Revisión sistemática de la literatura [Classification of fibromyalgia: A systematic review of the literature]. Reumatología Clínica, 5(2), 55-62. https://doi.org/10.1016/j.reuma.2008.07.001.

Bellato, E., Marini, E., Castoldi, F., Barbasetti, N., Mattei, L., Bonasia, D. E., \& Blonna, D. (2012). Fibromyalgia syndrome: Etiology, pathogenesis, diagnosis, and treatment. Pain Research and Treatment, 2012, Article ID 426130. https: / / doi.org/10.1155/2012/426130.

Bennett, R. M., Bushmakin, A. G., Cappelleri, J. C., Zlateva, G., \& Sadosky, A. B. (2009). Minimal clinically important difference in the Fibromyalgia Impact Questionnaire. The Journal of Rheumatology, 36(6), 1304-1311. https:/ / doi.org/ 10.3899/jrheum.081090.

Bernardy, K., Klose, P., Welsch, P., \& Häuser, W. (2018). Efficacy, acceptability and safety of cognitive behavioural therapies in fibromyalgia syndrome: A systematic review and meta-analysis of randomized controlled trials. European Journal of Pain, 22(2), 242-260. https:/ / doi.org/10.1002/ ejp.1121.

Bucourt, E., Martaillé, V., Goupille, P., Joncker-Vannier, I., Huttenberger, B., Réveillère, C., Mulleman, D., \& Courtois, R. (2019). A comparative study of fibromyalgia, rheumatoid arthritis, spondyloarthritis, and Sjögren's syndrome: Impact of the disease on quality of life, psychological adjustment, and use of coping strategies. Pain Medicine, 22, 372-381. https://doi.org/10.1093/pm/pnz255.

Burckhardt, C. S., Clark, S. R., \& Bennett, R. M. (1991). The Fibromyalgia Impact Questionnaire: Development and validation. Journal of Rheumatology, 18(5), 728-733.

Buysse, D. J., Reynolds, C. F., III, Monk, T. H., Berman, S. R., \& Kupfer, D. J. (1989). The Pittsburgh Sleep Quality Index: A new instrument for psychiatric practice and research. Psychiatry Research, 28(2), 193-213. https:/ / doi.org/ 10.1016/0165-1781(89)90047-4.

Calandre, E. P., García-Carrillo, J., García-Leiva, J. M., RicoVillademoros, F., Molina-Barea, R., \& Rodríguez-López, C. M. (2011). Subgrouping patients with fibromyalgia according to the results of the Fibromyalgia Impact Questionnaire: A replication study. Rheumatology International, 31, 1555-1559. https:/ / doi.org/10.1007/ s00296-010-1521-3.

Cheng, S.-T., Leung, C. M. C., Chan, K. L., Chen, P. P., Chow, Y. F., Chung, J. W. Y., Law, A. C. B., Lee, J. S. W., Leing, E. M. F., \& Tam, C. W. C. (2018). The relationship of selfefficacy to catastrophizing and depressive symptoms in community-dwelling older adults with chronic pain: A 
moderated mediation model. PLOS ONE, 13(9), Article e0203964. https:// doi.org/10.1371/journal.pone.0203964.

Collado, A., Gómez, E., Coscolla, R., Sunyol, R., Solé, E., Rivera, J., Altarriba, E., Carbonell, J., \& Castells, X. (2014). Work, family and social environment in patients with fibromyalgia in Spain: An epidemiological study. EPIFFAC study. BMC Health Services Research, 14, Article 513. https:/ / doi.org/10.1186/s12913-014-0513-5.

Crombez, G., Eccleston, C., Van Damme, S., Vlaeyen, J. W. S., \& Karoly, P. (2012). Fear-avoidance model of chronic pain: The next generation. The Clinical Journal of Pain, 28(6), 475-485. https:/ / doi.org/10.1097/ AJP.0b013e3182385392.

Crombez, G., Eccleston, C., van den Broeck, A., Goubert, L., \& van Houdenhove, B. (2004). Hypervigilance to pain in fibromyalgia: The mediating role of pain intensity and catastrophic thinking about pain. The Clinical Journal of Pain, 20(2), 98-102. http:/ / doi.org/10.1097/00002508-20040300000006.

Derogatis, L. R. (1994). SCL-90-R. Symptom Checklist-90Revised. Administration, scoring and procedures manual. NCS Pearson.

de Souza, J. B., Goffaux, P., Julien, N., Potvin, S., Charest, J., \& Marchand, S. (2009). Fibromyalgia subgroups: Profiling distinct subgroups using the Fibromyalgia Impact Questionnaire: A preliminary study. Rheumatology International, 29, 509-515. https://doi.org/10.1007/ s00296008-0722-5.

Docampo, E., Collado, A., Escaramís, G., Carbonell, J., Rivera, J., Vidal, J., Alegre, J., Rabionet, R., \& Estivill, X. (2013). Cluster analysis of clinical data identifies fibromyalgia subgroups. PLOS ONE, 8(9), Article e74873. https://doi.org/10.1371/journal.pone.0074873.

Écija, C., Luque-Reca, O., Suso-Ribera, C., Catala, P., \& Peñacoba, C. (2020). Associations of cognitive fusion and pain catastrophizing with fibromyalgia impact through fatigue, pain severity, and depression: An exploratory study using structural equation modeling. Journal of Clinical Medicine, 9(6), Article 1763. https:/ / doi.org/10.3390/ jcm9061763.

Estévez-López, F., Segura-Jiménez, V., Álvarez-Gallardo, I. C., Borges-Cosic, M., Pulido-Martos, M., CarbonellBaeza, A., Aparicio, V. A., Geenen, R., \& DelgadoFernández, M. (2017). Adaptation profiles comprising objective and subjective measures in fibromyalgia: The Al-Andalus project. Rheumatology, 56(11), 2015-2024. https:/ / doi.org/10.1093/rheumatology/kex302.

Fillion, L., Gélinas, C., Simard, S., Savard, J., \& Gagnon, P. (2003). Validation evidence for the French Canadian adaptation of the Multidimensional Fatigue Inventory as a measure of cancer-related fatigue. Cancer Nursing, 26(2), 143-154. http: / / doi.org/10.1097 / 00002820-20030400000008.

Follick, B. T., Cherry, B. J., Rutledge, D. N., Zettel-Watson, L., \& Jones, C. J. (2016). Heterogeneity in fibromyalgia based upon cognitive and physical performance and psychological symptomology. Journal of the American Association of Nurse Practitioners, 28(1), 19-30. https: / / doi.org/10.1002/23276924.12270.

Font, T., Bordoy, C., Mas, A. J., Seoane-Mato, D., Álvarez, F., Delgado, M., Martínez, C., Sánchez-Fernández, S. A., Rojas, L. M., García, P. V., Olivé, A., Rubio, P., Larrosa, M.,
Navarro, N., Sánchez-Piedra, C., Díaz-González, F., Bustabad-Reyes, S., \& the Working Group Proyecto EPISER2016. (2020). Prevalence of fibromyalgia and associated factors in Spain. Clinical and Experimental Rheumatology, 38(123), S47-S52.

Formann, A. K. (1984). Die latent-class-analyse: Einfuhrung in die theorie und anwendung [Class-latent analysis: Introduction to theory and application]. Beltz.

Galvez-Sánchez, C. M., \& Reyes del Paso, G. A. (2020). Diagnostic criteria for fibromyalgia: Critical review and future perspectives. Journal of Clinical Medicine, 9(4), Article 1219. https: / / doi.org/10.3390/jcm9041219.

García-Campayo, J., Rodero, R., Alda, M., Sobradiel, N., Montero, J., \& Moreno, S. (2008). Validación de la versión española de la Escala de la Catastrofización ante el Dolor (Pain Catastrophizing Scale) en la fibromialgia [Validation of the Spanish version of the Pain Catastrophizing Scale in fibromyalgia]. Medicina Clínica, 131(13), 487-492. https: / / doi.org/10.1157/13127277.

Giesecke, T., Williams, D. A., Harris, R. E., Cupps, T. R., Tian, X., Tian, T. X., Gracely, R. H., \& Clauw, D. J. (2003). Subgrouping of fibromyalgia patients on the basis of pressure-pain thresholds and psychological factors. Arthritis E Rheumatism, 48(10), 2916-2922. https: / / doi.org/10.1002/ art.11272.

Gonzalez, B., Novo, R., \& Peres, R. (2020). Personality and psychopathology heterogeneity in MMPI-2 and healthrelated features in fibromyalgia patients. Scandinavian Journal of Psychology. https:/ / doi.org/10.1111/sjop.12694.

González de Rivera, J. L., de las Cuevas, C., RodríguezAbuín, M., \& Rodríguez-Pulido, F. (2002). SCL-90-R. Cuestionario de 90 sintomas [SCL-90-R. Symptom Checklist90-Revised]. TEA Ediciones.

Häuser, W., Perrot, S., Clauw, D. J., \& Fitzcharles, M. A. (2018). Unravelling fibromyalgia-steps toward individualized management. The Journal of Pain, 19(2), 125-134. https: / / doi.org/10.1016/j.jpain.2017.08.009.

Hegarty, R. S. M., Fletcher, B. D., Conner, T. S., Stebbings, S., \& Treharne, G. J. (2020). Acceptance and commitment therapy for people with rheumatic disease: Existing evidence and future directions. Musculoskeletal Care, 18(3), 330-341. https://doi.org/10.1002/msc.1464.

Hita-Contreras, F., Martínez-López, E., Latorre-Román, P. A., Garrido, F., Santos, M. A., \& Martínez-Amat, A. (2014). Reliability and validity of the Spanish version of the Pittsburgh Sleep Quality Index (PSQI) in patients with fibromyalgia. Rheumatology International, 34, 929-936. https://doi.org/10.1007/s00296-014-2960-z.

Horta-Baas, G., \& Romero-Figueroa, M. d. S. (2019). Selfreported disability in women with fibromyalgia from a tertiary care center. Advances in Rheumatology, 59, Article 45. https:/ /doi.org/10.1186/s42358-019-0086-4.

Lami, M. J., Martínez, M. P., Miró, E., Sánchez, A. I., \& Guzmán, M. A. (2018). Catastrophizing, acceptance, and coping as mediators between pain and emotional distress and disability in fibromyalgia. Journal of Clinical Psychology in Medical Settings, 25(1), 80-92. https://doi.org/10.1007/ s10880-018-9543-1.

Leeuw, M., Goossens, M. E. J. B., Linton, S. J., Crombez, G., Boersma, K., \& Vlaeyen, J. W. S. (2007). The fear-avoidance model of musculoskeletal pain: Current state of scientific 
evidence. Journal of Behavioral Medicine, 30(1), 77-94. https: / / doi.org/10.1007/s10865-006-9085-0.

Loevinger, B. L., Shirtcliff, E. A., Muller, D., Alonso, C., \& Coe, C. L. (2012). Delineating psychological and biomedical profiles in a heterogeneous fibromyalgia population using cluster analysis. Clinical Rheumatology, 31(4), 677-685. https://doi.org/10.1007/s10067-011-1912-1.

Luciano, J. V., García-Forero, C., Cerdà-Lafont, M., Peñarrubia-María, M. T., Fernández-Vergel, R., CuestaVargas, A. I., Ruíz, J. M., Rozadilla-Sacanell, A., SirventAlierta, E., Santo-Panero, P., García-Campayo, J., SerranoBlanco, A., Pérez-Aranda, A., \& Rubio-Valera, M. (2016). Functional status, quality of life, and costs associated with fibromyalgia subgroups: A latent profile analysis. The Clinical Journal of Pain, 32(10), 829-840. https:/ / doi.org/ 10.1097/ AJP.0000000000000336.

Lledó-Boyer, A., Pastor-Mira, M., Pons-Calatayud, N., LópezRoig, S., Rodríguez-Marín, J., \& Bruehl, S. (2010). Control beliefs, coping and emotions: Exploring relationships to explain fibromyalgia health outcomes. International Journal of Clinical and Health Psychology, 10(3), 459-476.

Marques, A. P., Assumpção, A., Matsutani, L. A., Pereira, C. A. B., \& Lage, L. (2008). Pain in fibromyalgia and discriminative power of the instruments: Visual analog scale, dolorimetry and the McGill Pain Questionnaire. Acta Reumatologica Portuguesa, 33, 345-351.

Martín-Aragón, M., Pastor, M. A., Rodríguez-Marín, J., March, M. J., Lledó, A., López-Roig, S., \& Terol, M. C. (1999). Percepción de autoeficacia en dolor crónico. Adaptación y validación de la Chronic Pain Self-efficacy Scale [Perceived self-efficacy in chronic pain. Adaptation and validation of the Chronic Pain Self-efficacy Scale]. Revista de Psicología de la Salud, 11(1), 53-75.

Martínez, M. P., Miró, E., Sánchez, A. I., Díaz-Piedra, C., Cáliz, R., Vlaeyen, J. W. S., \& Buela-Casal, G. (2014). Cognitive-behavioral therapy for insomnia and sleep hygiene in fibromyalgia: A randomized controlled trial. Journal of Behavioral Medicine, 37, 683-697. https: / / doi.org/ 10.1007/s10865-013-9520-y.

Martínez, M. P., Miró, E., Sánchez, A. I., Lami, M. J., Prados, G., \& Ávila, D. (2014). Spanish version of the Pain Vigilance and Awareness Questionnaire: Psychometric properties in a sample of women with fibromyalgia. The Spanish Journal of Psychology, 17, Article E105. https:/ / doi.org/10.1017/ sjp.2014.108.

McCracken, L. M. (1997). "Attention” to pain in persons with chronic pain: A behavioral approach. Behavior Therapy, 28(2), 271-284. https: / / doi.org/10.1016/S0005-7894(97) 80047-0.

McCracken, L. M., \& Morley, S. (2014). The psychological flexibility model: A basis for integration and progress in psychological approaches to chronic pain management. Journal of Pain, 15(3), 221-234. https: / / doi.org/10.1016/ j.jpain.2013.10.014.

McCracken, L. M., Vowles, K. E., \& Eccleston, C. (2004). Acceptance of chronic pain: Component analysis and revised assessment method. Pain, 107(1-2), 159-166. https: / / doi.org/10.1016/j.pain.2003.10.012.

Melzack, R. (1987). The Short-Form Mcgill Pain Questionnaire. Pain, 30(2), 191-197. https: / / doi.org/10.1016/0304-3959(87) 91074-8.
Muller, V., Chan, F., Iwanaga, K., Wu, J.-R., Chen, X., Lee, B., Tao, J., Rumrill, P., \& Bezyak, J. (2020). An empirically derived taxonomy of biopsychosocial factors of adjustment to fibromyalgia: Results of a multivariate analysis. Rehabilitation Counseling Bulletin, 64(1), 3-16. https: / / doi.org/10.1177\%2F0034355220925157.

Munguía-Izquierdo, D., Segura-Jiménez, V., CamilettiMoirón, D., Pulido-Martos, M., Álvarez-Gallardo, I. C., Romero, A., Aparicio, V. A., Carbonell-Baeza, A., \& Delgado-Fernández, M. (2012). Multidimensional Fatigue Inventory: Spanish adaptation and psychometric properties for fibromyalgia patients. The Al-Andalus study. Clinical \& Experimental Rheumatology, 30, S94-S102.

Okifuji, A., \& Hare, B. D. (2013). Management of fibromyalgia syndrome: Review of evidence. Pain E Therapy, 2, 87-104. https:/ / doi.org/10.1007/s40122-013-0016-9.

Pardos-Gascón, E. M., Narambuena, L., Leal-Costa, C., \& vander Hofstadt-Román, C. J. (2021). Differential efficacy between cognitive-behavioral therapy and mindfulnessbased therapies for chronic pain: Systematic review. International Journal of Clinical and Health Psychology, 21(1), Article 100197. https:/ / doi.org/10.1016/j.ijchp.2020.08.001.

Pérez-Aranda, A., Andrés-Rodríguez, L., Feliu-Soler, A., Núñez, C., Stephan-Otto, C., Pastor-Mira, M. A., LópezRoig, S., Peñacoba, C., Calandre, E. P., Slim, M., Salgueiro, M., Feixas, G., \& Luciano, J. V. (2019). Clustering a large Spanish sample of patients with fibromyalgia using the Fibromyalgia Impact Questionnaire-Revised: Differences in clinical outcomes, economic costs, inflammatory markers, and gray matter volumes. Pain, 160(4), 908-921. https: / / doi.org/10.1097/j.pain.0000000000001468.

Plazier, M., Ost, J., Stassijns, G., de Ridder, D., \& Vanneste, S. (2015). Pain characteristics in fibromyalgia: Understanding the multiple dimensions of pain. Clinical Rheumatology, 34, 775-783. https: / / doi.org/10.1007/s10067-014-2736-6.

Prados, G., Miró, E., Martínez, M. P., Sánchez, A. I., Lami, M. J., \& Cáliz, R. (2020). Combined cognitive-behavioral therapy for fibromyalgia: Effects on polysomnographic parameters and perceived sleep quality. International Journal of Clinical and Health Psychology, 20(3), 232-242. https: / / doi.org/10.1016/j.ijchp.2020.04.002.

Rehm, S. E., Koroschetz, J., Gockel, U., Brosz, M., Freynhagen, R., Tölle, T. R., \& Baron, R. (2010). A crosssectional survey of 3035 patients with fibromyalgia: Subgroups of patients with typical comorbidities and sensory symptom profiles. Rheumatology, 49(6), 1146-1152. https:/ / doi.org/10.1093/rheumatology/keq066.

Rivera, J., \& González, T. (2004). The Fibromyalgia Impact Questionnaire: A validated Spanish version to assess the health status in women with fibromyalgia. Clinical $\mathcal{E}$ Experimental Rheumatology, 22, 554-560.

Rodero, B., García-Campayo, J., Casanueva, B., López del Hoyo, Y., Serrano-Blanco, A., \& Luciano, J. V. (2010). Validation of the Spanish version of the Chronic Pain Acceptance Questionnaire (CPAQ) for the assessment of acceptance in fibromyalgia. Health $\mathcal{E}$ Quality of Life Outcomes, 8, Article 37. https:/ / doi.org/10.1186/1477-7525-8-37.

Sahar, K., Thomas, S. A., \& Clarke, S. P. (2016). Adjustment to fibromyalgia: The role of domain-specific self-efficacy and acceptance. Australian Journal of Psychology, 68(1), 29-37. https:/ / doi.org/10.1111/ajpy.12089. 
Salaffi, F., Mozzani, F., Draghessi, A., Atzeni, F., Catellani, R., Ciapetti, A., Di Carlo, M., \& Sarzi-Puttini, P. (2016). Identifying the symptom and functional domains in patients with fibromyalgia: Results of a cross-sectional Internet-based survey in Italy. Journal of Pain Research, 9, 279-286. http:/ / doi.org/10.2147/JPR.S100829.

Salgueiro, M., Aira, Z., Buesa, I., Bilbao, J., \& Azkue, J. J. (2012). Is psychological distress intrinsic to fibromyalgia syndrome? Cross-sectional analysis in two clinical presentations. Rheumatology International, 32, 3463-3469. https:/ / doi.org/10.1007/s00296-011-2199-x.

Smets, E. M. A., Garssen, B., Bonke, B., \& de Haes, J. C. J. M. (1995). The Multidimensional Fatigue Inventory (MFI): Psychometric qualities of an instrument to assess fatigue. Journal of Psychosomatic Research, 39(3), 315-325. https: / / doi.org/10.1016/0022-3999(94)00125-O.

Sullivan, M. J. L., Bishop, S. R., \& Pivik, J. (1995). The Pain Catastrophizing Scale: Development and validation. Psychological Assessment, 7(4), 524-532. https:/ / doi.org/ 10.1037/1040-3590.7.4.524.

Tangen, S. F., Helvik, A.-S., Eide, H., \& Fors, E. A. (2020). Pain acceptance and its impact on function and symptoms in fibromyalgia. Scandinavian Journal of Pain, 20(4), 727-736. https: / / doi.org/10.1515/sjpain-2020-0049.

Thieme, K., \& Turk, D. C. (2006). Heterogeneity of psychophysiological stress responses in fibromyalgia syndrome patients. Arthritis Research \& Therapy, 8, Article R9. https://doi.org/10.1186/ar1863.

Thieme, K., Mathys, M., \& Turk, D. C. (2017). Evidencedbased guidelines on the treatment of fibromyalgia patients: Are they consistent and if not, why not? Have effective psychological treatments been overlooked? The Journal of Pain, 18(7), 747-756. https:/ / doi.org/10.1016/ j.jpain.2016.12.006.

Thieme, K., Turk, D. C., \& Flor, H. (2004). Comorbid depression and anxiety in fibromyalgia syndrome: Relationship to somatic and psychosocial variables. Psychosomatic Medicine, 66(6), 837-844. https:/ / doi.org/ 10.1097/01.psy.0000146329.63158.40.

Thieme, K., Turk, D. C., Gracely, R. H., Maixner, W., \& Flor, H. (2015). The relationship among psychological and psychophysiological characteristics of fibromyalgia patients. Journal of Pain, 16(2), 186-196. https:/ / doi.org/10.1016/ j.jpain.2014.11.009.

Thompson, M., \& McCracken, L. M. (2011). Acceptance and related processes in adjustment to chronic pain. Current Pain $\mathcal{E}$ Headache Reports, 15, 144-151. https: / / doi.org/10.1007/ s11916-010-0170-2.

Torres, X., Bailles, E., Valdés, M., Gutiérrez, F., Peri, J.-M., Arias, A., Gómez, E., \& Collado, A. (2013). Personality does not distinguish people with fibromyalgia but identifies subgroups of patients. General Hospital Psychiatry, 35(6), 640-648. https://doi.org/10.1016/ j.genhosppsych.2013.07.014.

Trainor, H., Baranoff, J., Henke, M., \& Winefield, H. (2019). Functioning with fibromyalgia: The role of psychological flexibility and general psychological acceptance. Australian Psychologist, 54(3), 214-224. https:/ / doi.org/10.1111/ ap.12363.
Triñanes, Y., González-Villar, A., Gómez-Perretta, C., \& Carrillo de la Peña, M. T. (2014). Profiles in fibromyalgia: Algometry, auditory evoked potentials and clinical characterization of different subtypes. Rheumatology International, 34, 1571-1580. https: / / doi.org/10.1007/ s00296-014-3007-1.

Turk, D. C., Okifuji, A., Sinclair, J. D., \& Starz, T. W. (1996). Pain, disability, and physical functioning in subgroups of patients with fibromyalgia. Journal of Rheumatology, 23(7), 1255-1262.

Turk, D. C., Okifuji, A., Sinclair, J. D., \& Starz, T. W. (1998). Differential responses by psychosocial subgroups of fibromyalgia syndrome patients to an interdisciplinary treatment. Arthritis Care E Research, 11(5), 397-404. https: / / doi.org/10.1002/art.1790110511.

Veehof, M. M., Trompetter, H. R., Bohlmeijer, E. T., \& Schreurs, K. M. G. (2016). Acceptance-and mindfulnessbased interventions for the treatment of chronic pain: A meta-analytic review. Cognitive Behaviour Therapy, 45(1), 5-31. https:/ / doi.org/10.1080/16506073.2015.1098724.

Velasco-Furlong, L., Gutiérrez-Hermoso, L., Mateos-Pintado, B., Garvi-de Castro, D., Blanco-Rico, S., SanrománCanelada, L., López-Roig, S., Pastor-Mira, M. A., \& Peñacoba-Puente, C. (2020). The 4 U's rule of fibromyalgia: A proposed model for fatigue in a sample of women with fibromyalgia: A qualitative study. International Journal of Environmental Research and Public Health, 17(17), Article 6224. https:/ / doi.org/10.3390/ijerph17176224.

Verra, M. L., Angst, F., Brioschi, R., Lehmann, S., Keefe, F. J., Staal, J. B., de Bie, R. A., \& Aeschlimann, A. (2009). Does classification of persons with fibromyalgia into Multidimensional Pain Inventory subgroups detect differences in outcome after a standard chronic pain management program? Pain Research \& Management, 14(6), Article ID 137901. https:/ / doi.org/10.1155/2009/137901.

Vincent, A., Hoskin, T. L., Whipple, M. O., Clauw, D. J., Barton, D. L., Benzo, R. P., \& Williams, D. A. (2014). OMERACT-based fibromyalgia symptom subgroups: An exploratory cluster analysis. Arthritis Research \& Therapy, 16, Article 463. https: / / doi.org/10.1186/s13075-014-0463-7.

Wilson, H. D., Robinson, J. P., \& Turk, D. C. (2009). Toward the identification of symptom patterns in people with fibromyalgia. Arthritis Care \& Research, 61(4), 527-534. https://doi.org/10.1002/art.24163.

Wolfe, F., Clauw, D. J., Fitzcharles, M.-A., Goldenberg, D. L., Katz, R. S., Mease, P., Russell, A. S., Russell, I. J., Winfield, J. B., \& Yunus, M. B. (2010). The American College of Rheumatology preliminary diagnostic criteria for fibromyalgia and measurement of symptom severity. Arthritis Care and Research, 62(5), 600-610. https:/ /doi.org/ 10.1002/acr.20140.

Wolfe, F., Smythe, H. A., Yunus, M. B., Bennett, R. M., Bombardier, C., Goldenberg, D. L., Tugwell, P., Campbell, S. M., Abeles, M., Clark, P., Fam, A. G., Farber, S. J., Fiechtner, J. J., Franklin, C. M., Gatter, R. A., Hamaty, D., Lessard, J., Lichtbroun, A. S., Masi, A. T., ... Sheon, R. P. (1990). The American College of Rheumatology 1990 criteria for the classification of fibromyalgia. Arthritis \& Rheumatism, 33(2), 160-172. https:/ / doi.org/10.1002/art.1780330203. 
Yim, Y.-R., Lee, K.-E., Park, D. J., Kim, S.-H., Nah, S.-S., Lee, J. H., Kim, S.-K., Lee, Y.-A., Hong, S. J., Kim, H. A., Lee, H. S., Kim, H. A., Joung, C. I., Kim, S. H., \& Lee, S. S. (2017). Identifying fibromyalgia subgroups using cluster analysis: Relationships with clinical variables. European Journal of Pain, 21(2), 374-384. https://doi.org/10.1002/ejp.935.

\section{Appendix}

\section{Data Transparence}

The present study is part of a larger research on psychological evaluation and intervention in fibromyalgia (FM). A part of the FM patients of this study participated in a psychometric study aimed at establishing the reliability and validity of Spanish adaptation of several cognitive-affective measures about pain. In addition, a part of the FM patients of this study was included in a randomized controlled trial to compare the efficacy of various psychological intervention programs. Since these are studies with very different objectives and methodology, the data collected have been (and/or will foreseeably be) presented in separate papers. The present study constitutes an original use of data, does not overlap with the aforementioned studies, and has not been published previously. 